\title{
Ultrasonic-assisted rapid cold welding of bulk metallic glasses
}

\author{
Zhiyuan Huang, Jianan Fu, Xin Li, Wenxin Wen, Hongji Lin, Yan Lou, Feng Luo, Zhenxuan Zhang, \\ Xiong Liang and Jiang $\mathrm{Ma}^{*}$
}

\begin{abstract}
Glass-forming ability is a long-standing concern in the field of metallic glasses (MGs), which greatly limits their maximum casting size and extensive applications. In this work, we report an ultrasonic-assisted rapid cold welding of bulk MGs without using any additives. MGs with various compositions are welded together under a $20,000-\mathrm{Hz}$ highfrequency ultrasonic vibration without losing their amorphous nature. The ultrasonic technology offers the advantages of rapid bonding $(<1 \mathrm{~s})$ at low temperature (near room temperature) and low stress $(<1 \mathrm{MPa})$. According to the phenomenon observed in the experiment, the activated fresh atoms diffuse through the broken channel port under continuous rupture of the oxide layer, and the ultrasonic vibration accelerates the atomic-diffusion process. Finally, stable bonding of the MG interface is realized. This universal ultrasonic-assisted welding process can realize the composition design of dissimilar MGs as well as tuning of new materials with new performance.
\end{abstract}

Keywords: metallic glass, glass-forming ability, ultrasonicassisted welding, atomic diffusion, composition design

\section{INTRODUCTION}

Under rapid cooling after melting, the atoms of some metals become disordered [1,2]; the thus formed materials are called amorphous alloys or metallic glasses (MGs). This unique structure allows MGs to possess more excellent mechanical properties [3-8], magnetic properties $[9,10]$, high-performance electrocatalysis [11-14], industrial wastewater treatment ability $[15,16]$, and other advantages than traditional metals. Its discovery can be traced back to the 1930s, when Kramer [17] first reported amorphous-alloy films. In the 1960s, MG ribbons were prepared [18]. Then, in the 1980s, a 1-mm-diameter MG was realized [19]. Currently, the largest MG in the world has an 80$\mathrm{mm}$ diameter, although it is based on a noble metal [20]. Achieving the maximum size of an MG that can be cast, i.e., the glass-forming ability (GFA), has been a core scientific problem in this field and greatly limits the wide applications of MGs [21]. The GFA limits of Cu-based [22], Ni-based [23], and Fe-based [24] MGs are 12, 3, and $16 \mathrm{~mm}$, respectively. The size of casting MGs is often limited to a small range, and MGs with a larger size contain non-metallic or Be elements [24-26]. To achieve a breakthrough in the GFA of MGs, scholars have proposed various types of combination technology [27-46].
Laser welding [33], welding [28], and other methods require melting and subsequent rapid quenching of MGs to ensure reformation of amorphous alloys [32]. These bonding methods require extreme heat to melt the MGs and a rapid cooling rate to re-solidify them. This type of liquid-phase welding suffers from the disadvantage of insufficient cooling rate, which can lead to partial crystallization of MGs and make the interface fragile. Welding in a supercooled liquid region (SLR) is another potential method of realizing an MG bulk, such as thermoplastic forming (TPF) [37,42]. This method uses the rapid increase in fluidity in the SLR. Atoms with reduced viscosity enter the surface through a broken oxide layer, forming a stable connection [40]. This method requires a wide SLR. Therefore, the optional composition is limited, and the increase in temperature shortens the MG-crystallization relaxation time.

The introduction of ultrasound opens the door for MG cold bonding [44-48]. To overcome the disadvantages of the previously mentioned welding process, a strategy to create bulk MG involves the use of ultrasonic-vibration-bonding technology. In our previous work [45], the MG has lower surface activation energy, and the high-frequency vibration reduces the viscosity of surface atoms by several orders of magnitude. In the present work, atomic diffusion between two MG surfaces can be achieved at low temperatures, low stress, and low ultrasonic energy. The X-ray diffraction (XRD) and differential scanning calorimetry (DSC) results show that the obtained welding samples still maintain their amorphous nature. The morphology of the interface, change in the oxygen content, and diffusion of the elements confirm the bonding process of ultrasonic welding. This ultrasonic-assisted bonding process offers a breakthrough of the GFA of MGs, realizes composition design of dissimilar MGs, and allows tuning of new materials with novel performance.

\section{EXPERIMENTAL SECTION}

\section{Sample preparation}

$\mathrm{La}_{55} \mathrm{Al}_{25} \mathrm{Ni}_{15} \mathrm{Cu}_{10} \mathrm{Co}_{5}, \mathrm{Pt}_{57.5} \mathrm{Ni}_{14.7} \mathrm{Cu}_{5.3} \mathrm{P}_{22.5}$ (Pt-based MG), $\mathrm{Zr}_{35}$ $\mathrm{Ti}_{30} \mathrm{Cu}_{8.25} \mathrm{Be}_{26.75}$ (Zr-based MG1), $\mathrm{Zr}_{65} \mathrm{Cu}_{17.5} \mathrm{Ni}_{10} \mathrm{Al}_{7.5}$ (Zr-based MG2), $\mathrm{Zr}_{47} \mathrm{Cu}_{46} \mathrm{Al}_{7}$, and $\mathrm{Pd}_{40} \mathrm{Ni}_{10} \mathrm{Cu}_{30} \mathrm{P}_{20}$ (Pd-based MG) bulk MGs were used in the present research. To ensure the uniform fusion of all single metals (purity $>99 \mathrm{wt} \%$ ), the alloys were repeatedly melted six times by arc-melting followed by dropcasting onto a $\mathrm{Cu}$ mold to obtain MG rods. Then, the rods were cut into 2-mm thickness using a low-speed diamond cutting

Shenzhen Key Laboratory of High Performance Nontraditional Manufacturing, College of Mechatronics and Control Engineering, Shenzhen University, Shenzhen 518060, China

* Corresponding author (email: majiang@szu.edu.cn) 
machine, and the surface was polished using 400, 1000, and 2000 sandpaper. Subsequently, a high-frequency ultrasonic vibration of $20 \mathrm{kHz}$ was introduced to weld the MG, as shown in Fig. 1a. The ultrasonic amplitude was $80 \%$ of the maximum amplitude value, the trigger pressure was $22 \mathrm{~N}$, and the welding stress was $150 \mathrm{kPa}$. These parameters were controllable, and only the welding energy was adjusted from 50 to $150 \mathrm{~J}$. For the components with low atomic activation energy, the welding energy was correspondingly reduced. To study the gradient nanostructure molding, different nanowire structures of the La-Pt-based MG were fabricated at the surface by one-step TPF in SLR using an anodized aluminum oxide (AAO) mold with half $200-\mathrm{nm}$ and half 300 -nm through holes.

\section{Characterization}

Thermal images of the ultrasonic welding were captured using an infrared imaging camera (Fotric 280d) with a macro lens. Real-time measurement of the pressure was performed using a self-made dynamometer, and a data-acquisition card (National Instruments NI-9237) with a sampling frequency of $2 \mathrm{kHz}$ was used to process and transmit the data to a computer. After the ultrasonic bonding of the MGs, their amorphous nature was characterized using XRD (Rigaku miniflex600) with $\mathrm{Cu}-\mathrm{Ka}$ radiation at a scanning rate of $5^{\circ} \mathrm{min}^{-1}$ from $20^{\circ}$ to $80^{\circ}$. The glass-transition temperature $T_{\mathrm{g}}$ and crystallization temperature $T_{\mathrm{x}}$ of the welded sample were confirmed by DSC (PerkinElmer
DSC8000) at a heating rate of $20 \mathrm{~K} \mathrm{~min}^{-1}$. The amorphous atom arrangement, interface microstructure, and surface element distribution were obtained using the high angle annular dark field (HAADF) and the selected-area electron diffraction (SAED) images were obtained by a scanning transmission electron microscope (TEM) with double spherical aberration correctors (Cs-STEM). Finally, the morphology of the bonding interface and surface nanowires was collected using a fieldemission scanning electron microscope (SEM) (FEI QUANTA FEG 450).

\section{RESULTS AND DISCUSSION}

The ultrasonic-assisted bonding of MGs was performed at room temperature under a $20-\mathrm{kHz}$ high-frequency vibration (Fig. 1a). The work-stress curve varied with time during the ultrasonic welding (Fig. 1b). The entire welding time was less than $1 \mathrm{~s}$, and the welding stress was lower than $1 \mathrm{MPa}$. In addition, the fluctuation range of the welding stress was positively correlated with the energy set in this study. The optical images of different types of MG weldments (Fig. 1c) (where S1 is Pt-Pt-based MG, S2 is Pt-La-based MG, S3 is La-La-based MG, S4 is Pd-Pd-based MG, S5 is Zr-Zr-based MG1, and S6 is tZr-Zr-based MG2) show that the welding sample surfaces are complete. The results demonstrate that ultrasonic vibration could suitably bond various matrix MGs without using any additive. The welding temperature increases with the increase in energy. Among the results, the a

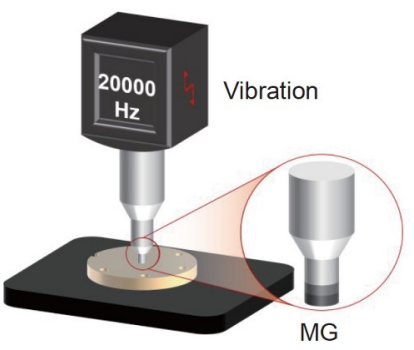

d

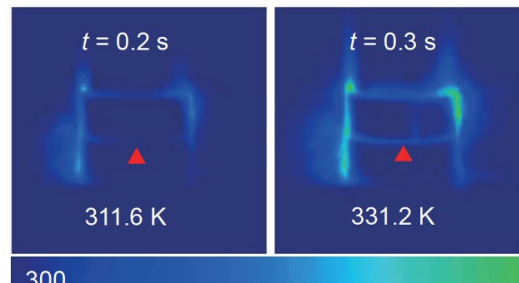

300

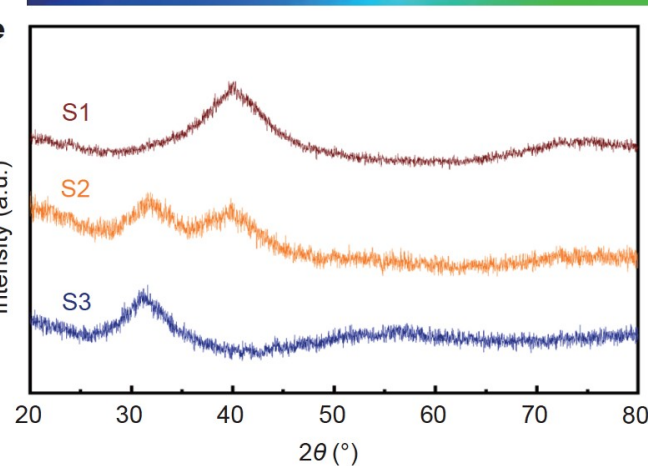

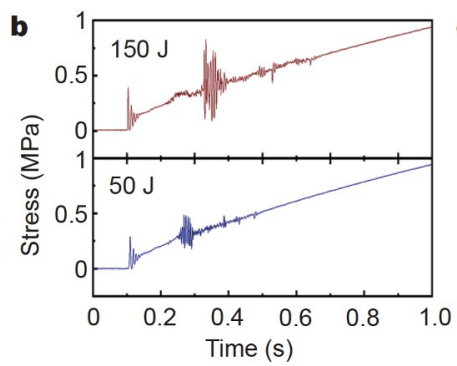
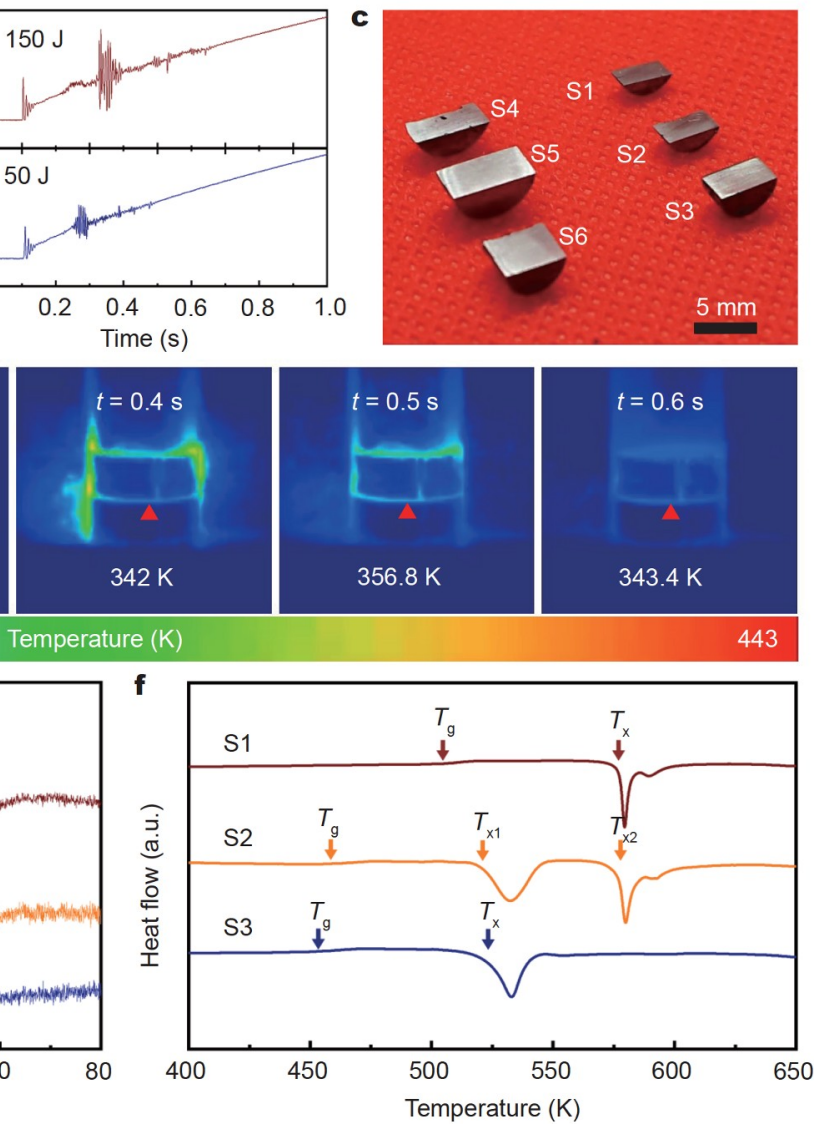

Figure 1 (a) Schematic of ultrasonic vibration welding. (b) Under energy values of 50 and $150 \mathrm{~J}$, the welding stress of the MG changes with time. (c) Optical image of the welding samples, namely, Pt-Pt-based MG (S1), Pt-La-based MG (S2), La-La-based MG (S3), Pd-Pd-based MG (S4), Zr-Zr-based MG1 (S5), and Zr-Zr-based MG2 (S6). (d) Temperature change during ultrasonic welding of S5. (e) XRD patterns of S1, S2, and S3 showing their amorphous nature. (f) DSC curves of S1, S2, and S3, which show their $T_{\mathrm{g}}$ and $T_{\mathrm{x}}$. 
temperature change of S5 at 150-J energy demonstrates the maximum temperature at the interface (Fig. 1d). The temperature peak is $356.8 \mathrm{~K}$, which is approximately $58 \%$ of $T_{\mathrm{x}}$ and $41 \%$ of melting temperature $T_{1}$ [25]. This temperature is even lower than the $T_{\mathrm{g}}(465.2 \mathrm{~K})$ of the La-based MG, which requires the smallest amount of energy. This cold-joint method ensures the amorphous nature of MG. Theoretically, the increase in steadystate temperature depends on loss modulus $G$ of MGs, which can be expressed as [48]

$$
G^{\prime \prime}=\frac{2 v \mathrm{e}^{-\frac{\Delta G}{k T}} \beta \Omega \mu^{2} \omega k T}{\left[2 v \mathrm{e}^{-\frac{\Delta G}{k T}}(k T+\beta \Omega \mu)\right]^{2}+\omega k T^{2}},
$$

where $k$ is the Boltzmann constant, $T$ is the ambient temperature, $\omega$ is the angular frequency of the external agitation, $\Delta G$ is the activation energy of the local relaxation event, $v$ is the attempted frequency of the local relaxation sites, $\mu$ is the nonrelaxed modulus, and $\beta \Omega$ is the effective activation volume of the local stress-relaxation events.

According to Molinari and Germain [49], the temperature change due to cyclic loading can be obtained by solving the following heat-conduction equation:

$$
-\frac{\kappa}{r} \frac{\mathrm{d}}{\mathrm{d} r}\left(r \frac{\mathrm{d} T}{\mathrm{~d} r}\right)=\frac{3}{2} \omega \varepsilon_{0}^{2} G^{\prime \prime}[\omega, T(r)],
$$

where $\kappa$ is the thermal conductivity, $r$ is the axial distance in a cylindrical coordinate, $\varepsilon_{0}$ is the amplitude of the resulting cyclic strain, and the right-hand side of the equation represents the heat generated due to anelasticity. To verify that the MG did not experience crystallization under ultrasonic vibration, the XRD curves of S1, S2, and S3 exhibit a typical break similar to Bragg diffraction peaks in the range of $30^{\circ}-40^{\circ}$, whereas no Bragg diffraction peak in the crystal is observed at other angles
(Fig. 1e). The DSC curves further verify the amorphous nature of the MG (Fig. 1f). The $T_{\mathrm{g}}$ values of $\mathrm{S} 1$ and $\mathrm{S} 3$ are 508 and $465 \mathrm{~K}$, respectively, and their $T_{\mathrm{x}}$ values are 580 and $520 \mathrm{~K}$, respectively. In addition, La-Pt-based MG reveals the combination of S1 and S3. Only slight differences in the thermal parameters exist between the ultrasonic-welding-treated and as-cast MG samples. The results show that the ultrasonic-assisted rapid cold welding of MGs retains their amorphous nature.

The ultrasonic-assisted rapid cold welding of MGs supplants the traditional hot-welding method (Fig. 2). The possible welding processes of MGs are listed in Table 1 . The welding temperatures of these processes range from 300 to $3000 \mathrm{~K}$. Most of the MG welding processes use the method of first melting and then rapid cooling of the MG to realize the combination of two MGs. The typical critical cooling rates $\left(R_{\mathrm{c}}\right)$ are on the order of $10^{2}-10^{6} \mathrm{~K} \mathrm{~s}^{-1}[1,2,50,51]$. Therefore, adapting a liquid-phase welding to achieve an amorphous stage has become a great challenge. When a lower cooling rate $R_{\text {cryst }}$ is achieved, local and total crystallization of MGs occur; thus, the welding interface becomes fragile and will fracture. The temperature and timedependent transformation from amorphous to the crystalline state of MGs can be characterized by a time-temperaturetransformation (TTT) curve that is shaped similar to a nose. The other welding processes use the characteristics of viscosity reduction in the SLR to realize MG bonding. These processes can also achieve a stable bonding interface, but the implementation time is relatively long. On the other hand, the welded MG components are extremely limited and usually require a wide SLR. In contrast, ultrasonic welding of MGs is a fast and low-temperature welding method. Thus, it consumes the lowest energy in achieving bonding of MGs without crystallization. The ultrasonic-assisted cold-welding technology not only avoids the problem of rapid cooling speed required by the laser and other liquid-phase welding processes but also overcomes the problem
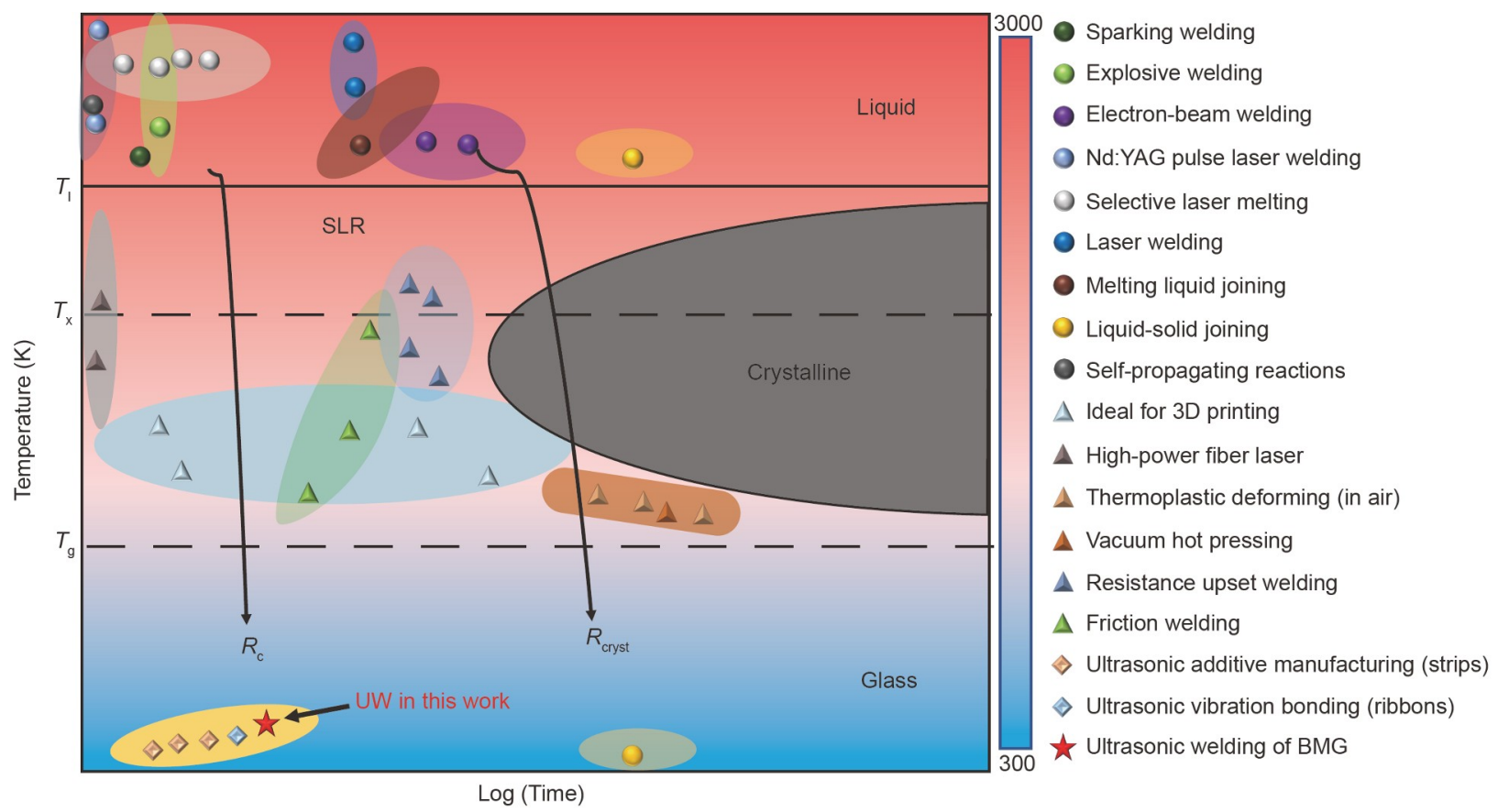

Figure 2 TTT diagram. The high-temperature welding processes must match rapid cooling rate $R_{\mathrm{c}}$ to achieve a disordered atomic structure. Insufficient cooling rate $R_{\text {cryst }}$ can lead to partial crystallization of MGs and make the interface fragile. The ultrasonic vibration welding process is always at a low temperature that is very far from the TTT curve, which effectively ensures the amorphous state of MGs. 
Table 1 Bulk-bonding technology of MG

\begin{tabular}{|c|c|c|c|}
\hline Technical Name & Material & Temperature $(\mathrm{K})$ & Time (ms) \\
\hline Sparking welding [26] & $\mathrm{Zr}_{55} \mathrm{Al}_{10} \mathrm{Ni}_{5} \mathrm{Cu}_{30}$ & $>1100$ & 25 \\
\hline Electron-beam welding $[28,29]$ & $\underset{\mathrm{Zr}_{41} \mathrm{Be}_{23} \mathrm{Ti}_{14} \mathrm{Cu}_{30} \mathrm{Ni}_{10}}{\mathrm{Zr}_{55} \mathrm{Al}_{10}}$ & $>1030$ & $200-500$ \\
\hline Nd: YAG pulse laser welding [30] & $\mathrm{Cu}_{54} \mathrm{Ni}_{6} \mathrm{Zr}_{22} \mathrm{Ti}_{18}$ & $1500-2550$ & $4-10$ \\
\hline Selective laser melting [31] & $\mathrm{Fe}_{74} \mathrm{Mo}_{4} \mathrm{P}_{10} \mathrm{C}_{7.5} \mathrm{~B}_{2.5} \mathrm{Si}_{2}$ & $>T_{1}$ & $>0$ \\
\hline Laser welding $[32,33]$ & $\begin{array}{c}\mathrm{Zr}_{55} \mathrm{Cu}_{30} \mathrm{Al}_{10} \mathrm{Ni}_{5} \\
\mathrm{Ti}_{40} \mathrm{Zr}_{25} \mathrm{Ni}_{3} \mathrm{Cu}_{12} \mathrm{Be}_{20}\end{array}$ & $1800-2300$ & $\sim 500$ \\
\hline Melting liquid Joining [34] & $\mathrm{Zr}_{55} \mathrm{Cu}_{30} \mathrm{Al}_{10} \mathrm{Ni}_{5}$ & 1273 & $>0$ \\
\hline Liquid-solid joining [35] & $\begin{array}{c}\mathrm{Zr}_{51} \mathrm{Ti}_{5} \mathrm{Ni}_{10} \mathrm{Cu}_{25} \mathrm{Al}_{9} \mathrm{Zr}_{50.7} \mathrm{Cu}_{28} \\
\mathrm{Ni}_{9} \mathrm{Al}_{12.3}\end{array}$ & 1123 and 300 & $40-70$ \\
\hline Self-propagating reactions [36] & $\mathrm{Zr}_{57} \mathrm{Ti}_{5} \mathrm{Cu}_{20} \mathrm{Ni}_{8} \mathrm{Al}_{10}$ & 1350 & 0.01 \\
\hline $3 \mathrm{D}$ printing [37] & $\mathrm{Zr}_{44} \mathrm{Ti}_{11} \mathrm{Cu}_{10} \mathrm{Ni}_{10} \mathrm{Be}_{25}$ & $>T_{\mathrm{g}}$ & $>0$ \\
\hline High-power fiber laser [38] & $\mathrm{Zr}_{55} \mathrm{Al}_{10} \mathrm{Ni}_{5} \mathrm{Cu}_{30}$ & $\sim T_{\mathrm{x}}$ & $\sim 1$ \\
\hline Thermoplastic deforming [39] & $\mathrm{Zr}_{35} \mathrm{Ti}_{30} \mathrm{Cu}_{7.5} \mathrm{Be}_{27.5}$ & $>T_{\mathrm{g}}$ & $>0$ \\
\hline Vacuum hot pressing $[40]$ & $\mathrm{Al}_{75} \mathrm{Ni}_{10} \mathrm{Ti}_{10} \mathrm{Zr}_{5}$ & 733 & $1.2 \times 10^{6}$ \\
\hline Resistance upset welding [41] & Zr-based MG & $695.8-729.3$ & $1300-2200$ \\
\hline Friction welding [42] & $\begin{array}{c}\mathrm{Zr}_{41.5} \mathrm{Ti}_{13.8} \mathrm{Cu}_{12.5} \mathrm{Ni}_{10} \mathrm{Be}_{22.5} \\
\mathrm{Zr}_{50} \mathrm{Cu}_{40} \mathrm{Al}_{10}\end{array}$ & $733-787$ & $200-800$ \\
\hline Ultrasonic AM (strips) [43] & $\mathrm{Ni}_{82.2} \mathrm{Cr}_{7} \mathrm{~B}_{3} \mathrm{Si}_{4.8} \mathrm{Fe}_{3}$ & 300 & $30-90$ \\
\hline Ultrasonic-vibration bonding (ribbons) [44] & $\begin{array}{c}\mathrm{La}_{55} \mathrm{Al}_{25} \mathrm{Ni}_{5} \mathrm{Cu}_{10} \mathrm{Co}_{5} \mathrm{Pd}_{40} \mathrm{Cu}_{30} \\
\mathrm{P}_{20} \mathrm{Ni}_{10} \mathrm{Zr}_{35} \mathrm{Ti}_{30} \mathrm{Cu}_{8.25} \mathrm{Be}_{26.75}\end{array}$ & 300 & $0-1000$ \\
\hline Ultrasonic cold joining MG [45] & $\mathrm{La}_{55} \mathrm{Al}_{25} \mathrm{Ni}_{15} \mathrm{Cu}_{10} \mathrm{Co}_{5}$ & $<350$ & $0-1000$ \\
\hline Ultrasonic-assisted welding of BMGs & $\begin{array}{c}\mathrm{Pt}_{57.5} \mathrm{Ni}_{14.7} \mathrm{Cu}_{5.3} \mathrm{P}_{22.5} \\
\mathrm{Zr}_{35} \mathrm{Ti}_{30} \mathrm{Cu}_{8.25} \mathrm{Be}_{26.75} \\
\mathrm{Zr}_{65} \mathrm{Cu}_{17.5} \mathrm{Ni}_{10} \mathrm{Al}_{7.5} \\
\mathrm{Pd}_{40} \mathrm{Ni}_{10} \mathrm{Cu}_{30} \mathrm{P}_{20} \\
\mathrm{La}_{55} \mathrm{Al}_{25} \mathrm{Ni}_{15} \mathrm{Cu}_{10} \mathrm{Co}_{5}\end{array}$ & $<357$ & $0-1000$ \\
\hline
\end{tabular}

of long processing time in the SLR welding process such as TPF.

A gap existed at the beginning of La-La-based MG welding (Fig. 3a). Then, the gap disappeared, and no visual interface could be observed. This result shows that the interface could be completely bonded to the same substrate. During the ultrasonicassisted bonding of MGs with different substrates such as the PtLa-based MG (Fig. 3b), two types of MGs with different colors could be observed using SEM. Similarly, the welding interface reveals a complete individual, and no visual gap occurs. Because $150-\mathrm{J}$ welding energy was used in the ultrasonic-assisted welding of the Pd-Pd-based MG (Fig. 3c), the ultrasound worked longer and more violently vibrated; thus, some welding marks could be observed at high magnification. In our previous study, we found that the surface activation energy of MGs was lower than that of the bulk [45,52]. According to the molecular dynamics (MD) simulations of MGs under an ultrasonic vibration, the distribution of activation energy increases with different distances away from the surface (Fig. 3d). Surface atoms are more likely to pass through the damaged oxide layer into the matrix on the other side than the bulk atoms. The success of MG bonding is due to the activation and diffusion of surface atoms, and the atomic-level dynamics was characterized by the time-dependent mean-square displacements of particles at elapsed time $t$, which is defined as

$$
\left\langle r^{2}(\Delta t)\right\rangle=\frac{1}{N}\left\langle\sum_{i=1}^{N}\left|r_{i}(t)-r_{i}(0)\right|^{2}\right\rangle
$$

where $\left\langle r^{2}(\Delta t)\right\rangle$ denotes the ensemble average. The individual atomic dynamics of each atom was calculated as follows:

$r^{2}(\Delta t)=\left\|\vec{r}\left(t_{0}+\Delta t\right)\right\|$.

The atomic-scale deformation mechanism was analyzed by visualizing nonaffine-squared displacements $D_{j}^{2}$ [53], which is defined by

$D_{j}^{2}(t, \Delta t)=\frac{1}{N_{j}} \sum_{k \in N_{j}}\left[\overrightarrow{r_{j k}}(t)-\gamma_{j} \overrightarrow{r_{j k}}(t-\Delta t)\right]$,

where

$\gamma_{j}=Y_{j}^{-1} X_{j} Y_{j}=\sum_{k \in N_{j}}\left[\overrightarrow{r_{j k}}(t-\Delta t)\right]^{T}\left[\overrightarrow{r_{j k}}(t-\Delta t)\right]$.

The TEM graph shows the disordered arrangement of atoms (Fig. 3e), which is an enlarged image of Fig. 3f, and the diffractive halo-like SAED indicates a fully glassy feature. An imaginary red-atom model was used to indicate the diffusion of active atoms at the interface. The circular region was an enlarged model of the atom. The atom was closer to the oxide layer and required lower activation energy. After the diffused atoms combined, the La-Pt-based MG welding interface contained no gap (Fig. 3f). The white part in the figure is a Pt-based MG, and the black part is a La-based MG. To investigate the elemental distribution across the interface, an energy-dispersive spectroscopy (EDS) analysis was performed using TEM. Generally, the 

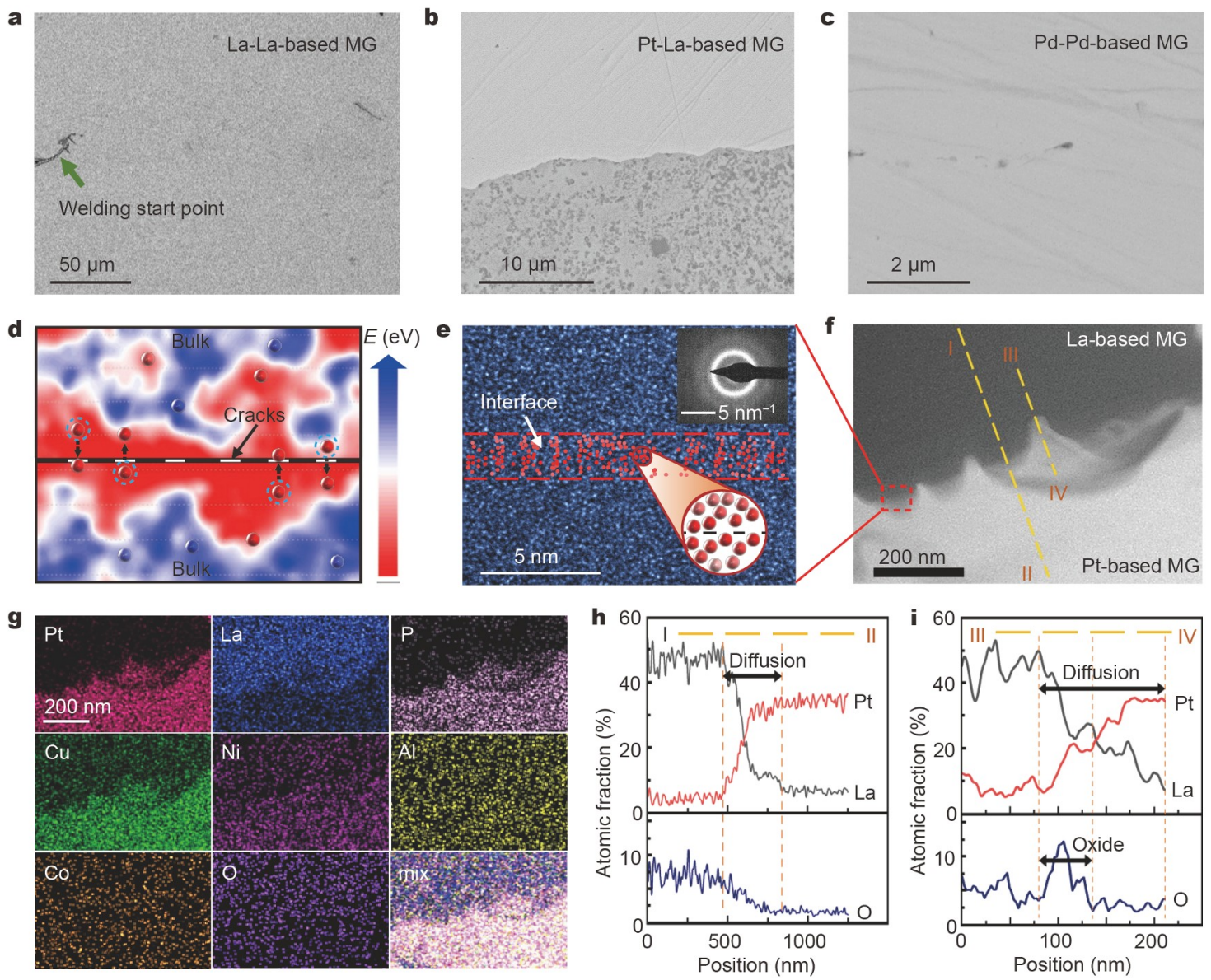

Figure 3 Characterization of the welding interface by SEM and TEM. (a) Interface of La-La-based MG. The black line at the left is the starting position of welding, and no other gap exists on the entire welding surface. (b) Interface image of the Pt-La-based MG. The welding interface can be clearly seen. (c) Higher magnification of the interface image of the Pd-Pd-based MG. (d) Schematic drawing of atomic mobility at the MG surface. The closer MG is to the interface, the lower is the energy required for atomic activation. (e) High-resolution TEM and SAED pattern of (inset) the Pt-La-based MG. The red spheres are hypothetical active atomic models. (f) Low-resolution TEM image of the Pt-La-based MG. (g) Elemental maps of the Pt-La-based MG. (h, i) Distribution of the linear elements perpendicular to the welding surface.

element distribution exhibits a clear boundary along the interface (Fig. 3g). We should note that some level of intermixing through diffusion could also be found from the EDS results. For instance, minor Pt and P were found in the La phase, whereas small amounts of $\mathrm{La}, \mathrm{Al}$, and Co were also found in the Pt phase. In this study, we need to point out that surface oxides at the surface of metals were generally unavoidable. The diffusion of $\mathrm{Pt}$ and La demonstrates an opposite relationship. The change in $\mathrm{O}$ in the broken oxide channel (Fig. $3 \mathrm{~h}$ ) was similar to that in La because $\mathrm{La}$ and $\mathrm{O}$ could easily form oxides. In addition, a rapid increase in $\mathrm{O}$ could be observed at the interface hindered by the oxide layer (Fig. 3i). Therefore, the formation of metallic bonding across the interface of the MGs clearly indicated that surface oxide layers, if they existed, must have been broken up into pieces during the metal-to-metal contact under the ultrasound, which proved the breakage of surface oxides during cold bonding.

The Pt-La-based MG composition was an artificial design using ultrasonic-assisted welding technology, and the cross section of La-Pt-based MG exhibited an undifferentiated whole (Fig. 4b). Subsequently, one-step TPF various scale Pt-La-based MG nanowires were obtained. In the TPF of the MGs, viscosity $\eta$ was usually approximately $10^{6}-10^{12} \mathrm{~Pa}$ s. Flow velocity $v$ was on the order of micrometers per second. Therefore, the following equation shows that the filling process of MGs is a simple laminar flow [54]:

$R_{\mathrm{e}}=\frac{\rho v D_{\mathrm{e}}}{\eta}$.

The calculation result is $R_{\mathrm{e}}<1$. According to the HagenPoiseuille flow, the relationship among the viscosity, filling time, pressure, micropore diameter, and filling length is expressed as follows [55]:

$P=32 v \cdot \eta \frac{L}{d^{2}}=32 \eta \cdot \frac{L}{d^{2}} \frac{\mathrm{d} L}{\mathrm{~d} t}$,

where $P$ is the pressure, $v$ and $\eta$ represent the velocity and viscosity of the viscous fluid flowing in the pipeline, respectively, and $L$ and $D$ are the length and diameter of the pipe, respectively. Considering that the interference of the capillary force significantly affects the nanometer-size filling process, the magnitude of the capillary force can be expressed as [56]

$f=\frac{4 \gamma \cos \theta}{D_{\mathrm{e}}}$,

where $\gamma$ is the vacuum interface energy of the MGs, which is approximately $1 \mathrm{~N} \mathrm{~m}^{-1}$, and $\theta$ is the contact angle between the 
a

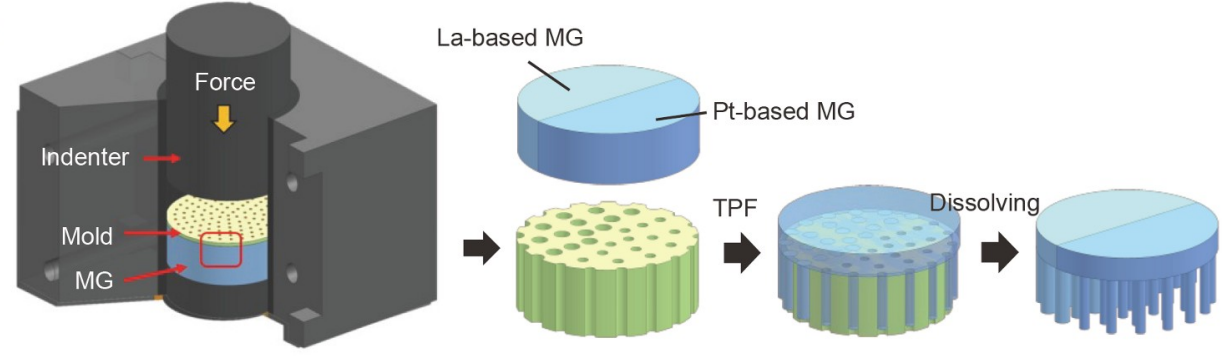

b

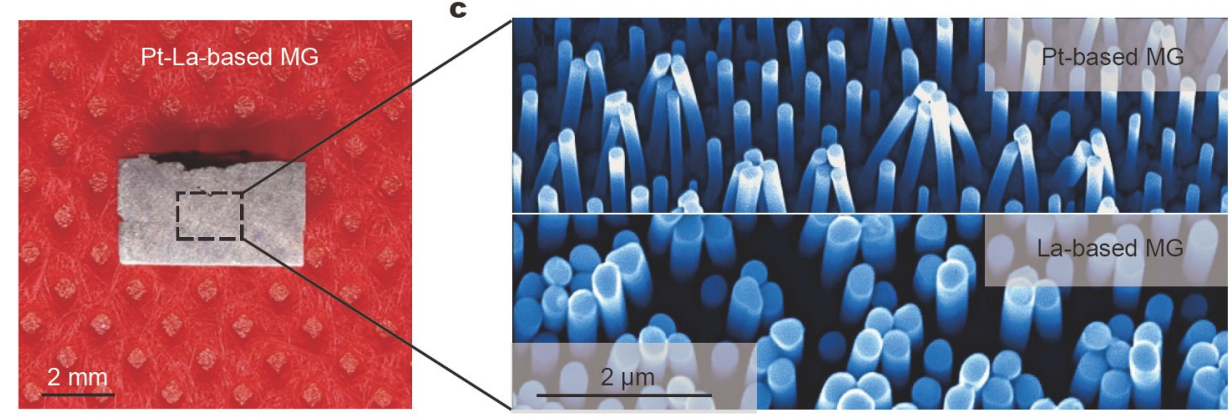

d
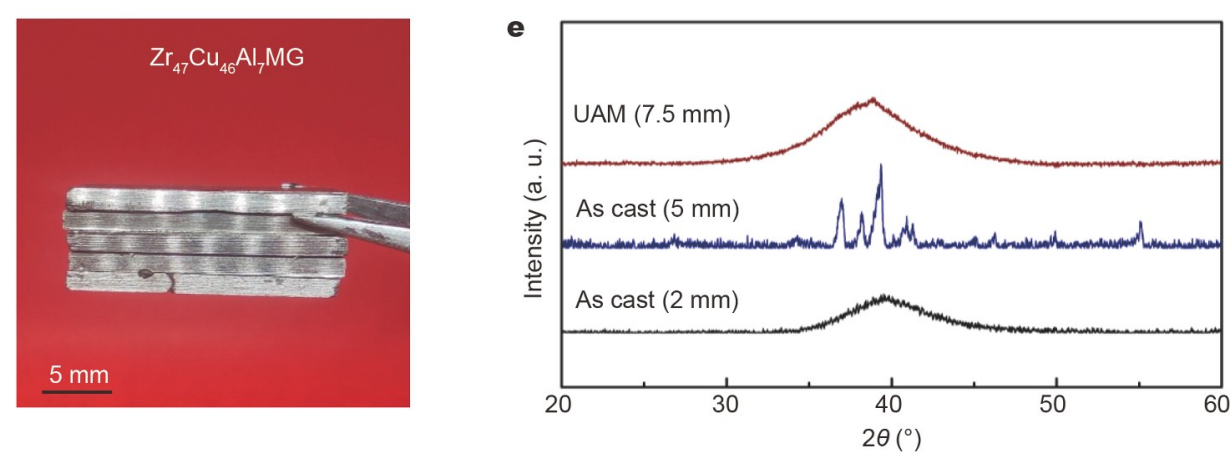

Figure 4 Application scenarios of ultrasonic welding of MGs. (a) Schematic of the TPF process. The MG nanowires were prepared using an AAO template with 200- and 300-nm pores, and the AAO template was dissolved in the $\mathrm{NaOH}$ solution. (b) Optical image of the welding sample, namely, La-Pt-based MG. (c) SEM images of the nanowires at the La-Pt-based MG surface, which was prepared by TPF under an applied force of $10 \mathrm{kN}$ and held for $20 \mathrm{~s}$ at $205^{\circ} \mathrm{C}$. (d) Optical image of multilayer $\mathrm{Zr}_{47} \mathrm{Cu}_{46} \mathrm{Al}_{7}$ MGs after ultrasonic-assisted welding. (e) XRD patterns of the as-cast MG and UAM samples. When the casting size reaches $5 \mathrm{~mm}$, the MG is seriously crystallized, whereas the MG prepared by UAM does not crystallize even when the casting size reaches $7.5 \mathrm{~mm}$.

viscous fluid and mold. The following equation was obtained:

$P=32 \eta \cdot \frac{L}{d^{2}} \frac{\mathrm{d} L}{\mathrm{~d} t}-\frac{4 \gamma \cos \theta}{D_{\mathrm{e}}}$.

We finally obtained the following equation:

$L=\sqrt{\frac{\left(P D_{\mathrm{e}}+4 \gamma \cos \theta\right) D_{\mathrm{e}} t}{32 \eta}}$.

The TPF diagram shows the MG replication structure of the AAO mold with 200- and 300-nm pores and the dissolution of the AAO template in the $\mathrm{NaOH}$ solution (Fig. 4a). In the TPF process, the viscosity of the MGs sharply decreased with the increase in temperature. At this time, a certain amount of stress was applied on the MG surface to realize the molding of micro/ nanostructure. The SEM images (Fig. 4c) show the 200- and 300$\mathrm{nm}$ gradient nanowires at the Pt-La-based MG surface, which were prepared by TPF under an applied force of $10 \mathrm{kN}$ and held for $20 \mathrm{~s}$ at $205^{\circ} \mathrm{C}$. For many glass-forming liquids, the temperature dependence of viscosity $\eta(T)$ for temperature intervals that lie between $T_{\mathrm{m}}$ and $T_{\mathrm{g}}$ can be described by the Vogel-Fulcher-Tamman (VFT) equation [57]:

$$
\eta(T)=\eta_{0} \exp \left(\frac{D^{*} \cdot T_{0}}{T-T_{0}}\right),
$$

where $\eta_{0}$ is constant, $\left(2.51 \times 10^{-5} \mathrm{Pas}\right.$ for $\mathrm{La}_{55} \mathrm{Al}_{25} \mathrm{Ni}_{15} \mathrm{Cu}_{10} \mathrm{Co}_{5}$ [58] and $4.5 \times 10^{-5} \mathrm{Pas}$ for $\mathrm{Pt}_{57.5} \mathrm{Ni}_{14.7} \mathrm{Cu}_{5.3} \mathrm{P}_{22.5}$ [59]); $T_{0}$ is the VFT temperature; $D^{*}$ is the kinetic-fragility parameter. Therefore, the MGs of different systems have different viscosity coefficients, and nanostructures with different lengths and sizes can be designed using Equation (11).

On the other hand, the ultrasonic-assisted rapid cold-welding technology could realize additive manufacturing of multiple MGs (Fig. 4d). The GFA of $\mathrm{Zr}_{47} \mathrm{Cu}_{46} \mathrm{Al}_{7}$ was $3 \mathrm{~mm}$. When the casting size was $2 \mathrm{~mm}$, the XRD results revealed that it was amorphous (Fig. 4e). In contrast, when the casting size $(5 \mathrm{~mm})$ was larger than the GFA, the XRD curve showed that the material contained a very serious crystallization peak. Fortunately, using the ultrasonic-assisted additive manufacturing (UAM) process, five pieces of $1.5-\mathrm{mm} \mathrm{MG}$ plates were bonded together, and the amorphous properties of the MGs were well preserved. The ultrasonic-assisted rapid cold-bonding technology offers a potential method for the design of bulk MGs. 


\section{CONCLUSIONS}

In contrast to other welding processes, ultrasonic-assisted bonding of MGs is a rapid ( $<1 \mathrm{~s})$ welding technology under lowtemperature (near room temperature) and low-stress $(<1 \mathrm{MPa})$ conditions. It effectively ensures the amorphous nature of MGs. The MG viscosity sharply decreases at the welding interface with the increase in the vibration frequency (from 0 to $20 \mathrm{kHz}$ ), and a very high internal surface friction occurs. Driven by low energy, the oxide layer at the MG surface is broken, and the original atoms are exposed. These atoms are activated under the action of ultrasonic vibration, diffuse through the broken oxide channel, and finally form a strong bridge among MGs. By using this technology, we can break through the GFA of MGs and realize the combination of different types of MGs. A 7.5-mm-thick $\mathrm{Zr}_{47} \mathrm{Cu}_{46} \mathrm{Al}_{7} \mathrm{MG}$ and the design of artificially controlled Pt-Labased MG composition and nanostructure were realized.

\section{Received 26 March 2021; accepted 31 May 2021; published online 29 July 2021}

1 Inoue A. Stabilization of metallic supercooled liquid and bulk amorphous alloys. Acta Mater, 2000, 48: 279-306

2 Wang WH, Dong C, Shek CH. Bulk metallic glasses. Mater Sci Eng-RRep, 2004, 44: 45-89

3 Telford M. The case for bulk metallic glass. Mater Today, 2004, 7: 3643

4 Pan J, Ivanov YP, Zhou WH, et al. Strain-hardening and suppression of shear-banding in rejuvenated bulk metallic glass. Nature, 2020, 578: 559-562

5 Trexler MM, Thadhani NN. Mechanical properties of bulk metallic glasses. Prog Mater Sci, 2010, 55: 759-839

6 Inoue A, Shen BL, Chang CT. Super-high strength of over $4000 \mathrm{MPa}$ for Fe-based bulk glassy alloys in $\left[\left(\mathrm{Fe}_{1-x} \mathrm{Co}_{x}\right)_{0.75} \mathrm{~B}_{0.2} \mathrm{Si}_{0.05}\right]_{96} \mathrm{Nb}_{4}$ system. Acta Mater, 2004, 52: 4093-4099

7 Schuh CA, Hufnagel TC, Ramamurty U. Mechanical behavior of amorphous alloys. Acta Mater, 2007, 55: 4067-4109

8 Lewandowski JJ, Wang WH, Greer AL. Intrinsic plasticity or brittleness of metallic glasses. Philos Mag Lett, 2005, 85: 77-87

9 Huang D, Li Y, Yang Y, et al. Soft magnetic Co-based Co-Fe-B-Si-P bulk metallic glasses with high saturation magnetic flux density of over 1.2 T. J Alloys Compd, 2020, 843: 154862

10 Lee H, Lee AY, Kim KI, et al. Nano-crystallization behavior and magnetic domain evolution in commercial $\mathrm{Fe}-\mathrm{Si}-\mathrm{B}$ metallic glass. J Alloys Compd, 2021, 857: 157565

11 Pang SJ, Zhang T, Asami K, et al. Synthesis of Fe-Cr-Mo-C-B-P bulk metallic glasses with high corrosion resistance. Acta Mater, 2002, 50: 489-497

12 Li MX, Zhao SF, Lu Z, et al. High-temperature bulk metallic glasses developed by combinatorial methods. Nature, 2019, 569: 99-103

13 Wang ZJ, Li MX, Yu JH, et al. Low-iridium-content IrNiTa metallic glass films as intrinsically active catalysts for hydrogen evolution reaction. Adv Mater, 2020, 32: 1906384

14 Yan Y, Wang C, Huang Z, et al. Highly efficient and robust catalysts for the hydrogen evolution reaction by surface nano engineering of metallic glass. J Mater Chem A, 2021, 9: 5415-5424

15 Hu YC, Sun C, Sun C. Functional applications of metallic glasses in electrocatalysis. ChemCatChem, 2019, 11: 2401-2414

16 Jia Z, Wang Q, Sun L, et al. Attractive in situ self-reconstructed hierarchical gradient structure of metallic glass for high efficiency and remarkable stability in catalytic performance. Adv Funct Mater, 2019, 29: 1807857

17 Kramer J. Produced the first amorphous metals through vapor deposition. Ann Phys, 1934, 19: 37

18 Klement Jun W, Willens RH, Duwez P. Non-crystalline structure in solidified gold-silicon alloys. Nature, 1960, 187: 869-870

19 Chen HS. Thermodynamic considerations on the formation and sta- bility of metallic glasses. Acta Metall, 1974, 22: 1505-1511

20 Nishiyama $\mathrm{N}$, Takenaka K, Miura $\mathrm{H}$, et al. The world's biggest glassy alloy ever made. Intermetallics, 2012, 30: 19-24

21 Wang WH. Bulk metallic glasses with functional physical properties. Adv Mater, 2009, 21: 4524-4544

22 Kim YC, Lee JC, Cha PR, et al. Enhanced glass forming ability and mechanical properties of new $\mathrm{Cu}$-based bulk metallic glasses. Mater Sci Eng-A, 2006, 437: 248-253

23 Lee JK, Bae DH, Yi S, et al. Effects of Sn addition on the glass forming ability and crystallization behavior in Ni-Zr-Ti-Si alloys. J Non-Crystalline Solids, 2004, 333: 212-220

24 Chen Q, Shen J, Zhang D, et al. A new criterion for evaluating the glassforming ability of bulk metallic glasses. Mater Sci Eng-A, 2006, 433: 155-160

25 Duan G, Wiest A, Lind M, et al. Bulk metallic glass with benchmark thermoplastic processability. Adv Mater, 2007, 19: 4272-4275

26 Men H, Pang SJ, Zhang T. Effect of Er doping on glass-forming ability of $\mathrm{Co}_{50} \mathrm{Cr}_{15} \mathrm{Mo}_{14} \mathrm{C}_{15} \mathrm{~B}_{6}$ alloy. J Mater Res, 2006, 21: 958-961

27 Kawamura Y, Ohno Y. Spark welding of $\mathrm{Zr}_{55} \mathrm{Al}_{10} \mathrm{Ni}_{5} \mathrm{Cu}_{30}$ bulk metallic glasses. Scripta Mater, 2001, 45: 127-132

28 Bataev IA, Tanaka S, Zhou Q, et al. Towards better understanding of explosive welding by combination of numerical simulation and experimental study. Mater Des, 2019, 169: 107649

29 Kagao S, Kawamura Y, Ohno Y. Electron-beam welding of Zr-based bulk metallic glasses. Mater Sci Eng-A, 2004, 375-377: 312-316

30 Kawamura Y, Shoji T, Ohno Y. Welding technologies of bulk metallic glasses. J Non-Crystalline Solids, 2003, 317: 152-157

31 Kim J, Lee $\mathrm{D}$, Shin $\mathrm{S}$, et al. Phase evolution in $\mathrm{Cu}_{54} \mathrm{Ni}_{6} \mathrm{Zr}_{22} \mathrm{Ti}_{18}$ bulk metallic glass Nd:YAG laser weld. Mater Sci Eng-A, 2006, 434: 194-201

32 Pauly S, Löber L, Petters R, et al. Processing metallic glasses by selective laser melting. Mater Today, 2013, 16: 37-41

33 Chen B, Shi T, Li M, et al. Crystallization of $\mathrm{Zr}_{55} \mathrm{Cu}_{30} \mathrm{Al}_{10} \mathrm{Ni}_{5}$ bulk metallic glass in laser welding: Simulation and experiment. Adv Eng Mater, 2015, 17: 483-490

34 Wang G, Huang YJ, Shagiev M, et al. Laser welding of $\mathrm{Ti}_{40} \mathrm{Zr}_{25} \mathrm{Ni}_{3}$ $\mathrm{Cu}_{12} \mathrm{Be}_{20}$ bulk metallic glass. Mater Sci Eng-A, 2012, 541: 33-37

35 Wang XM, Son K, Inoue A. Bulk metallic glass formation by melting liquid joining method. Mater Trans, 2008, 49: 1419-1422

36 Huang Y, Xue P, Guo S, et al. Liquid-solid joining of bulk metallic glasses. Sci Rep, 2016, 6: 30674

37 Swiston Jr. AJ, Besnoin E, Duckham A, et al. Thermal and microstructural effects of welding metallic glasses by self-propagating reactions in multilayer foils. Acta Mater, 2005, 53: 3713-3719

38 Gibson MA, Mykulowycz NM, Shim J, et al. 3D printing metals like thermoplastics: Fused filament fabrication of metallic glasses. Mater Today, 2018, 21: 697-702

39 Kawahito Y, Terajima T, Kimura H, et al. High-power fiber laser welding and its application to metallic glass $\mathrm{Zr}_{55} \mathrm{Al}_{10} \mathrm{Ni}_{5} \mathrm{Cu}_{30}$. Mater Sci Eng-B, 2008, 148: 105-109

40 Chen W, Liu Z, Schroers J. Joining of bulk metallic glasses in air. Acta Mater, 2014, 62: 49-57

41 Wei X, Han F, Wang X, et al. Fabrication of Al-based bulk metallic glass by mechanical alloying and vacuum hot consolidation. J Alloys Compd, 2010, 501: 164-167

42 Andreoli AF, Ponsoni JB, Soares C, et al. Resistance upset welding of Zr-based bulk metallic glasses. J Mater Processing Tech, 2018, 255: 760764

43 Shin HS, Park JS, Yokoyama Y. Dissimilar friction welding of tubular Zr-based bulk metallic glasses. J Alloys Compd, 2010, 504: S275-S278

$44 \mathrm{Wu} \mathrm{W}$, Jiang J, Li G, et al. Ultrasonic additive manufacturing of bulk Ni-based metallic glass. J Non-Crystalline Solids, 2019, 506: 1-5

45 Ma J, Yang C, Liu X, et al. Fast surface dynamics enabled cold joining of metallic glasses. Sci Adv, 2019, 5: eaax7256

46 Li X, Liang X, Zhang Z, et al. Cold joining to fabricate large size metallic glasses by the ultrasonic vibrations. Scripta Mater, 2020, 185: $100-104$

47 Luo F, Sun F, Li K, et al. Ultrasonic assisted micro-shear punching of amorphous alloy. Mater Res Lett, 2018, 6: 545-551 
48 Huo LS, Zeng JF, Wang WH, et al. The dependence of shear modulus on dynamic relaxation and evolution of local structural heterogeneity in a metallic glass. Acta Mater, 2013, 61: 4329-4338

49 Molinari A, Germain Y. Self heating and thermal failure of polymers sustaining a compressive cyclic loading. Int J Solids Struct, 1996, 33: 3439-3462

50 Inoue A, Takeuchi A. Recent development and application products of bulk glassy alloys. Acta Mater, 2011, 59: 2243-2267

51 Wang WH, Wang RJ, Li FY, et al. Elastic constants and their pressure dependence of $\mathrm{Zr}_{41} \mathrm{Ti}_{14} \mathrm{Cu}_{12.5} \mathrm{Ni}_{9} \mathrm{Be}_{22.5} \mathrm{Cl}$ bulk metallic glass. Appl Phys Lett, 1999, 74: 1803-1805

52 Li H, Li Z, Yang J, et al. Interface design enabled manufacture of giant metallic glasses. Sci China Mater, 2021, 64: 964-972

53 Falk ML, Langer JS. Dynamics of viscoplastic deformation in amorphous solids. Phys Rev E, 1998, 57: 7192-7205

54 Li Z, Huang Z, Sun F, et al. Forming of metallic glasses: Mechanisms and processes. Mater Today Adv, 2020, 7: 100077

55 Schroers J, Pham Q, Desai A. Thermoplastic forming of bulk metallic glass-A technology for MEMS and microstructure fabrication. J Microelectromech Syst, 2007, 16: 240-247

56 Kumar G, Tang HX, Schroers J. Nanomoulding with amorphous metals. Nature, 2009, 457: 868-872

57 Busch R, Schroers J, Wang WH. Thermodynamics and kinetics of bulk metallic glass. MRS Bull, 2007, 32: 620-623

58 Lu ZP, Li Y, Liu CT. Glass-forming tendency of bulk La-Al-Ni-Cu-(Co) metallic glass-forming liquids. J Appl Phys, 2003, 93: 286-290

59 Demetriou MD, Johnson WL, Samwer K. Rheology and ultrasonic properties of metallic glass-forming liquids. J Alloys Compd, 2009, 483: 650-654

Acknowledgements This work was supported by the Key Basic and Applied Research Program of Guangdong Province, China (2019B030302010), the National Natural Science Foundation of China (51871157, 51971150 and 51775351), the Science and Technology Innovation Commission Shenzhen (JCYJ20170412111216258), the National Key Research and Development Program of China (2018YFA0703605), and Shenzhen Basic Research Project (JCYJ20190808152409578). The authors also thank the Electron Microscope Center of Shenzhen University for the assistance in microscopy observation.

Author contributions Huang $\mathrm{Z}$ conducted the welding experiments and wrote the paper; $\mathrm{Fu}$ J and $\mathrm{Li} \mathrm{X}$ performed the interface observation; Wen $\mathrm{W}$ and Lin $\mathrm{H}$ contributed to the preparation process of metallic glasses; Lou $\mathrm{Y}$ and Luo F performed the MD simulation; Zhang $\mathrm{Z}$ and Liang $\mathrm{X}$ conducted the morphology experiments; Ma J supervised the work and contributed to the revision of the manuscript.

Conflict of interest The authors declare that they have no conflict of interest.

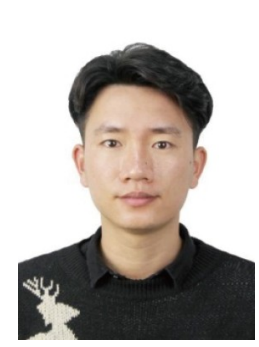

Zhiyuan Huang received his BSc degree in mechanical engineering from Southwest Jiaotong University in 2016 and MA degree from Shenzhen University, China, in 2020. He is currently a research assistant at the College of Mechatronics and Control Engineering, Shenzhen University. His research interests include metallic glasses, high-entropy alloy, and composite materials.

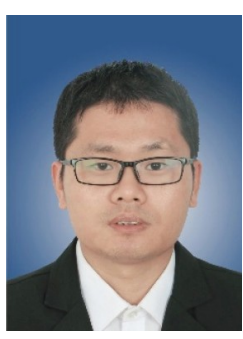

Jiang Ma received his BSc degree in materials science and engineering from Southeast University in 2009 and $\mathrm{PhD}$ degree from the Institute of Physics, Chinese Academy of Sciences (CAS), in 2014. He is currently a professor at the College of Mechatronics and Control Engineering, Shenzhen University. His research interests include metallic glass, high-entropy alloy, micro/nano precision forming, and functional surface fabrication and application.

\section{超声辅助快速冷焊接块体金属玻璃}

黄志远, 傅佳男, 李信, 温文馨, 林鸿基, 娄燕, 罗烽, 张振轩, 梁雄, 马将*

摘要 玻璃形成能力是金属玻璃领域中长期存在的问题, 它极大地限 制了金属玻璃的最大铸造尺寸和广泛应用. 在本研究中, 我们报道了超 声辅助快速冷焊接块体金属玻璃的方法. 在不需要焊料的情况下, 通过 20,000 赫兹的高频振动实现了不同组分金属玻璃的结合, 并且保证了金 属玻璃的非晶态特性. 超声技术有低温低压快速焊接的优点, 其中焊接 温度接近室温, 压强小于 $1 \mathrm{MPa}$, 焊接时间小于 $1 \mathrm{~s}$. 根据观察到的现象, 随着金属玻璃氧化层的不断破裂，金属玻璃被超声振动激活并通过破 裂的氧化层扩散到基体中, 同时超声振动加速了扩散的过程, 最终实现 金属玻璃界面的稳定结合. 这种普适性的超声辅助焊接工艺可以实现 金属玻璃的大块化, 以及不同组分的非晶态复合材料与新性能的设计. 